\title{
CONSERVAÇÃO DE ÁGUA DE COCO POR REFRIGERAÇÃO *
}

\author{
PAULO ROBERTO DE BARROS SALOMÃO DAVID ** \\ ZELYTA DE FARO FERNANDES ***
}

\begin{abstract}
Avaliou-se a qualidade do processo de envase $e$ refrigeração da água de coco verde (Cocus nucifera, L.) durante armazenamento de 24 e 48 horas. Amostras foram colhidas aleatoriamente para análises físicoquímicas (acidez total, pH, ${ }^{\circ}$ Brix e açúcares totais), microbiológicas (contagem padrão em placas, coliformes totais e fecais, bolores e leveduras) e sensoriais. A aceitabilidade do produto foi testada através da utilização do Teste Triangular Modificado. Os resultados evidenciaram que o processamento do produto foi adequado sob o ponto de vista sanitário. As análises físico-químicas e microbiológicas revelaram que todas as amostras encontraram-se de acordo com os padrões estabelecidos pela Legislação Brasileira. A áqua de coco apresentou-se em condições de consumo, após ter sido envasada e armazenada a temperatura de $10{ }^{\circ} \mathrm{C}$ pelo período de 48 horas. Houve leve alteração na cor do produto após período de 48 horas de armazenamento. No entanto, esta alteração não influiu na aceitabilidade do produto.
\end{abstract}

\section{INTRODUÇÃO}

No Brasil, a quase totalidade da produção de coco está voltada para a alimentação humana tanto na forma in natura como de produtos industrializados. Estima-se que 35 a $40 \%$ da produção destina-se às agroindústrias para a produção de farinha, leite, creme in natura para uso doméstico e $10 \%$ são comercializados como coco verde, para consumo da água. O restante da produção é comercializada de maneira informal para consumo doméstico em diversas aplicações culinárias regionais (6).

* Parte de monografia apresentada ao Departamento de Nutrição, Centro de Ciências da Saúde, Universidade Federal de Pernambuco, como requisito para obtenção do título de especialista em Controle de Qualidade de Alimentos.

** Engenheiro Químico graduado pela Universidade Católica de Pernambuco (UNICAP). (e-mail:proberto@nutricao.ufpe.br).

*** Prof ${ }^{a}$. Adjunta do Departamento de Nutrição, Universidade Federal de Pernambuco. (e-mail: zelyta@nutricao.ufpe.br). 
O interesse de produtores e grupos empresariais pela cultura do coco vem aumentando nos últimos anos, preferencialmente para a implantação de áreas com coqueiros anões. O consumo da água do fruto imaturo, de excelentes qualidades organolépticas (6), está aumentando no mercado interno numa extensão de $20 \%$ ao ano (5).

A água de coco engarrafada constitui-se em produto de grande aceitação nos locais que apresentam escassez de coco in natura, embora o processo seja pouco difundido na região nordeste (5).

Os altos custos envolvidos no transporte e distribuição, além do tempo e espaço requerido para a comercialização do fruto in natura, parecem inibir maior incremento no seu comércio. Por outro lado, é crescente a demanda por alimentos refrigerados e congelados, que conservam as características de alimento "fresco", mesmo quando armazenado por longos períodos. Contudo, as indústrias que processam o coco verde para obtenção da água enfrentam problemas de natureza enzimática e microbiológica, que aviltam as qualidades organolépticas e a potabilidade deste produto (7). Evidencia-se assim a importância de se realizar pesquisas sobre 0 aproveitamento da água de coco de forma mais racional, desenvolvendo estudos para encontrar procedimentos adequados de lavagem e desinfecção dos frutos, para posterior extração da água de coco, seguido de tratamentos para inibição ou mesmo inativação do seu sistema enzimático. Embora sejam encontrados trabalhos sobre a conservação da água de coco de maneira comercial, a literatura a respeito é escassa.

O presente trabalho pretende apresentar contribuição para o aproveitamento racional de tão precioso e saboroso subproduto do coco, mediante avaliação do processo de envase e refrigeração da água de coco verde.

\section{MATERIAL E MÉTODOS}

\subsection{MATÉRIA-PRIMA}

Foram utilizados frutos em estágio de maturação verde, da espécie Cocus nucifera, L., obtidos no comércio local (CEAGEPE), oriundos de plantações de Igarassu, cidade litorânea e integrante da região metropolitana de Recife - PE.

\subsection{MATERIAL}

- Garrafas plásticas de $300 \mathrm{~mL}$, com tampa e lacre

- Equipamento de refrigeração do tipo "bebedouro para água mineral" 
- Instrumento furador de coco

- Refratômetro de campo, mod. I - 375320-ausJENA

- Refrigerador do tipo doméstico

- Potenciômetro, pHmetro, mod.302.

\subsection{DESENHO EXPERIMENTAL}

Os equipamentos e utensílios utilizados no experimento foram devidamente lavados e higienizados para evitar possível contaminação da água durante o manuseio dos mesmos. $O$ equipamento de refrigeração, "bebedouro para água mineral", mereceu especial atenção em sua limpeza e higienização. O mesmo foi lavado internamente (recipiente que contém a água, tubulações e torneira) com detergente neutro, enxaguado e deixado de molho por 20 minutos em solução de água clorada, contendo cerca de $10 \mathrm{ppm}$ de cloro livre. Em seguida, efetuou-se novo enxágüe do equipamento com água destilada (estéril) e colheu-se amostra de água para ser analisada microbiologicamente.

O processo de obtenção da água de coco refrigerada foi desenvolvido segundo o fluxograma da Figura 1.

\subsubsection{Descrição das operações}

\subsubsection{Seleção}

Os frutos foram selecionados de acordo com o estágio de maturação, retirando-se os cocos anões, rachados e deteriorados.

\subsubsection{Lavagem e desinfecção}

A desinfecção dos frutos foi realizada por imersão, durante 30 minutos, em água clorada, contendo cerca de 20 ppm de cloro livre, oriundo de solução de hipoclorito de sódio (5,2\% de pureza). Em seguida efetuou-se a lavagem com água potável, a fim de retirar o excesso de cloro residual. Esta etapa teve como objetivo retirar os detritos aderidos à casca do fruto, assim como reduzir a contaminação por microrganismos.

\subsubsection{Resfriamento do fruto}

Os frutos foram imersos em tanque, com água gelada e gelo, pelo período de 1 hora, até atingirem temperatura interna (da água de coco) de cerca de $15^{\circ} \mathrm{C}$. Utilizou-se água e gelo de boa qualidade (potável). 
FIGURA 1 - FLUXOGRAMA DO PROCESSAMENTO DA ÁGUA DE COCO REFRIGERADA (Cocus nucifera, L. )

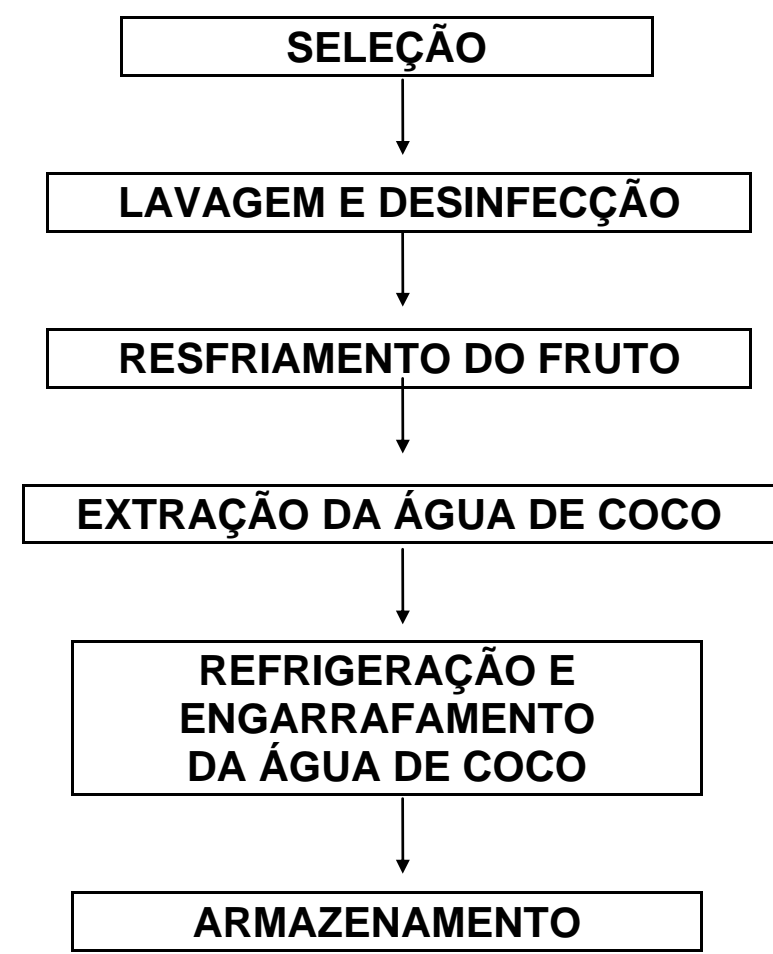

\subsubsection{Extração da água de coco}

Os cocos foram perfurados lateralmente e a água do fruto removida diretamente para o interior do recipiente de água do equipamento de refrigeração, com auxílio de um duto estéril.

\subsubsection{Refrigeração e engarrafamento da água de coco}

A água acondicionada no recipiente do equipamento de refrigeração foi ligeiramente refrigerada (até cerca $10^{\circ} \mathrm{C}$ ), sendo em seguida, engarrafada em recipiente plástico de $300 \mathrm{~mL}$, procedendo-se rápido fechamento das garrafas com tampa plástica de rosca e lacre. Nesta etapa coletou-se amostras para análises microbiológicas. 


\subsubsection{Armazenamento}

As garrafas foram colocadas em banho de gelo, sendo em seguida levadas para refrigerador (do tipo doméstico) e conservadas a temperatura de $10^{\circ} \mathrm{C}$, por 24 e 48 horas.

\subsection{CONTROLE DE QUALIDADE}

\subsubsection{Análises físico-químicas}

As amostras coletadas aleatoriamente foram submetidas às análises de acidez total, $\mathrm{pH}$, sólidos solúveis e açúcares totais.

Determinou-se a acidez titulável total mediante titulação com $0,1 \mathrm{~N} \mathrm{NaOH}$, segundo metodologia do Instituto Adolfo Lutz (9).

Para a determinação do $\mathrm{pH}$ foi utilizado $\mathrm{pHmetro}\left(\right.$ a $\left.25^{\circ} \mathrm{C}\right)$.

O ${ }^{\circ}$ Brix foi medido utilizando-se refratômetro.

Os açúcares totais foram determinados pelo método de Luff-Schoorl (10).

\subsubsection{Análises microbiológicas}

Foram realizadas as seguintes análises microbiológicas em amostra representativa de água de coco refrigerada: contagem de mesófilos aeróbios e anaeróbios facultativos (contagem padrão em placas), coliformes totais e fecais, bolores e leveduras, segundo metodologia da APHA (4). Os resultados foram comparados com padrões exigidos pela Legislação Brasileira (1).

\subsubsection{Análises sensoriais}

As análises sensoriais foram realizadas nos tempos de 24 e 48 horas, após a água de coco ter sido refrigerada e armazenada.

O painel foi composto por 20 (vinte) julgadores, treinados e não treinados, que utilizaram o Teste Triangular Modificado (3), conforme ficha apresentada na Figura 2. 
FIGURA 2 - MODELO DE QUESTIONÁRIO APRESENTADO PARA A REALIZAÇÃO DE ANÁLISE SENSORIAL DE ÁGUA DE COCO REFRIGERADA

NOME:

DATA:

PRODUTO: $\underline{\text { Água de Coco Refrigerada }}$

Neste grupo de 03 (três) amostras apresentadas, 02 (duas) são iguais e 01 (uma) é diferente. Avalie cuidadosamente cada amostra e coloque um círculo ao redor do número da amostra diferente:

Amostra $\mathrm{N}^{\circ}$.

Indique o grau de diferença entre a duplicata e a amostra diferente:
( ) Leve
( ) Grande
( ) Moderado
( ) Extremo

ACEITABILIDADE:

A amostra diferente é mais aceitável

( )

A duplicata de amostras é mais aceitável

COMENTÁRIOS:

Obrigado pela atenção! 
RESULTADOS E DISCUSSÃO

\subsection{RESULTADOS FÍSICO-QUÍMICOS}

Os resultados das determinações físico-químicas e de composição da água de coco refrigerada estão apresentados na Tabela 1.

TABELA 1 - CARACTERÍSTICAS FÍSICO-QUÍMICAS E DE COMPOSIÇÃO DE ÁGUA DE COCO REFRIGERADA

\begin{tabular}{c|c}
\hline DETERMINAÇÃO & RESULTADOS * \\
\hline $\mathrm{pH}$ & 5,05 \\
Acidez (\%) & 1,15 \\
Sólidos solúveis (\%) & 6,00 \\
Sólidos totais (\%) & 5,70 \\
Açúcares totais (\%) & 5,28 \\
\hline
\end{tabular}

* Os valores representam a média de três repetições.

Em relação ao $\mathrm{pH}$ a água de coco refrigerada apresentou valor de 5,05, sendo este compatível com os resultados encontrados por MACIEL (10), para a água de coco verde in natura (entre 4,70-6,45). Outros autores também afirmaram que a água de coco é uma solução de característica levemente ácida $(2,11)$.

Os resultados para sólidos solúveis ( $\left.{ }^{\circ} B r i x\right)$ e sólidos totais também foram compatíveis com os valores encontrados por MACIEL (10), 5,75\% e 5,00\%, respectivamente. A concentração de açúcares totais $(2,10 \%)$ encontrada por MACIEL (10) diverge do presente trabalho, o qual parece mais coerente com a quantidade de sólidos totais e ${ }^{\circ} B r i x$. Contudo, convém ressaltar que a composição de diferentes variedades de frutos, aliada às condições de crescimento da planta (solo, umidade, etc.), também podem afetar alguns parâmetros físico-químicos e de composição (12).

Os resultados das análises de $\mathrm{pH},{ }^{\circ}$ Brix e acidez (Tabela 2) mostram que a temperatura de refrigeração e o tempo de armazenamento não causaram efeitos significativos sobre os parâmetros físico-químicos.

\subsection{RESULTADOS MICROBIOLÓGICOS}

A contagem padrão realizada na água de enxágüe do equipamento de refrigeração (bebedouro) mostrou resultado igual a 1,0 UFC/mL, o que denota higienização eficiente do equipamento. 
TABELA 2 - VALORES DE pH, ${ }^{\circ}$ BRIX E ACIDEZ DETERMINADOS EM ÁGUA DE COCO VERDE ENGARRAFADA E ESTOCADA SOB REFRIGERAÇÃO POR 24 E 48 HORAS

\begin{tabular}{c|c|c|c}
\hline Determinações* & Tempo Zero & Após 24 horas & Após 48 horas \\
\hline $\mathrm{pH}$ & 5,05 & 5,04 & 5,05 \\
${ }^{\circ}$ Brix & 6,00 & 6,00 & 6,00 \\
Acidez & 1,15 & 1,20 & 1,15 \\
\hline
\end{tabular}

* Os valores representam a média de três repetições.

De acordo com a Tabela 3 houve pequena contaminação da água de coco refrigerada durante o processamento.

TABELA 3 - QUALIDADE MICROBIOLÓGICA DE ÁGUA DE COCO REFRIGERADA E ENGARRAFADA

\begin{tabular}{l|c}
\hline \multicolumn{1}{c|}{ ANÁLISES } & RESULTADOS \\
\hline Contagem padrão em placa $(\mathrm{UFC} / \mathrm{mL})$ & $1,6 \times 10^{2}$ \\
Bolores e leveduras $(\mathrm{UFC} / \mathrm{mL})$ & 60 \\
Coliformes totais $(\mathrm{NMP} / \mathrm{mL})$ & $1,0 \times 10^{2}$ \\
Coliformes fecais $(\mathrm{NMP} / \mathrm{mL})$ & ausente \\
\hline
\end{tabular}

A água de coco é uma solução ácida e estéril, que contém sais minerais e vários nutrientes, sendo sua microbiota inicial, ainda na palmeira, caracterizada pela presença de poucos microrganismos viáveis. Contudo, após a colheita, a estocagem no solo (em contato com areia e possivelmente esterco), o carregamento, o transporte e 0 descarregamento, a contaminação é disseminada $(8,12)$.

Como pode ser observado na Figura 1, antes da extração da água do fruto, o mesmo foi submetido a processo de lavagem, desinfecção e resfriamento, o que possivelmente reduziu a população microbiana presente no fruto. Todavia, durante o processamento, a transferência de 
parte destes microrganismos para a água foi inevitável. Estes resultados sugerem melhoria na definição do processo de limpeza do fruto e extração da água.

\subsection{AVALIAÇÃO SENSORIAL}

No primeiro experimento (24 horas após o início do armazenamento), a água de coco refrigerada apresentou diferença significativa ao nível de $p<0,05$, quando comparada com água de coco recentemente extraída do fruto (amostra de referência). O grau de diferença das amostras estabelecido pela equipe foi considerado entre leve e moderado. No entanto, foi alta a aceitabilidade da água de coco refrigerada, sendo a mesma mais apreciada que a amostra de referência. Contudo, o índice de diferença encontrado pode ter sofrido influência em relação ao nível de sabor doce, existente entre a amostra de referência e a amostra estudada, conforme comentários de alguns julgadores. Os atributos de adstringência e aroma não foram mencionados.

O segundo experimento sensorial, realizado 48 horas após o início do armazenamento, apresentou resultados similares aos do primeiro tempo. Neste experimento observou-se diferença extremamente significativa ao nível de $p<0,001$ entre as amostras analisadas. O grau de diferença entre as mesmas foi estabelecido como moderado e grande.

Paradoxalmente, a aceitabilidade da água de coco refrigerada foi altamente significativa ao nível de $p<0,001$. Uma possível justificativa para tal nível de diferença entre as amostras estudadas, parece estar relacionada, mais uma vez, com o acentuado sabor doce da água de coco refrigerada e engarrafada. Além disso, observou-se diferença de 1,30 ${ }^{\circ}$ Brix entre a amostra em estudo e a amostra tomada como referência. $O$ fato de em ambos experimentos ter ocorrido percepção acentuada do sabor doce entre as amostras estudadas foi mero acaso, visto que é impossível prever a doçura da água do fruto tomado como referência. Além da escolha do mesmo ser aleatória, a água de coco refrigerada e engarrafada resultou da mistura da água de vários frutos.

Outro fato que pode ter causado diferenciação no resultado foi a percepção, comentada por poucos julgadores, do aparecimento de leve coloração rósea na água de coco refrigerada, em relação à amostra de referência. Esta ligeira modificação na cor da solução analisada está provavelmente, ligada à existência de substâncias polifenólicas que podem funcionar como substrato para reações de escurecimento enzimático. Os resultados da análise sensorial estão apresentados na Tabela 4. 
TABELA 4 - AVALIAÇÃO SENSORIAL* REALIZADA EM ÁGUA DE COCO REFRIGERADA E ENGARRAFADA

\begin{tabular}{c|c|c|c}
\hline Análise sensorial & $\begin{array}{c}\text { Nível de } \\
\text { diferença }\end{array}$ & $\begin{array}{c}\text { Grau de } \\
\text { diferença }\end{array}$ & Nível de aceitabilidade \\
\hline Tempo (24 horas) & $\mathrm{p}<0,05$ & leve e moderado & $\mathrm{p}<0,001$ \\
\hline Tempo (48 horas) & $\mathrm{p}<0,001$ & moderado e grande & $\mathrm{p}<0,001$ \\
\hline
\end{tabular}

* Teste Triangular Modificado (3).

\title{
4 CONCLUSÃO
}

De acordo com os resultados pode-se concluir que:

- a água de coco apresentou-se em condições de consumo, após ter sido envasada e armazenada a temperatura de $10{ }^{\circ} \mathrm{C}$ pelo período de 48 horas;

- o processamento do produto foi adequado sob o ponto de vista sanitário. As análises físico-químicas e microbiológicas revelaram que todas as amostras encontraram-se de acordo com os padrões estabelecidos pela Legislação Brasileira;

- houve leve alteração na cor do produto após o período de 48 horas de armazenamento. No entanto, esta alteração não influiu na aceitabilidade do produto.

\begin{abstract}
The quality of the process of bottling and refrigerating coconut water from unripe coconut fruits (Cocus nucifera, L.) was evaluated for shelf-life period of 24 to 48 hours. Samples were picked up for physicochemical determinations (acidity, $\mathrm{pH}$, ${ }^{\circ}$ Brix, and total sugar content) for microbiological analysis (total bacterial count, total and fecal coliforms, molds, and yeast) and sensory evaluation. The acceptability of the product was evaluated by the Modified Triangular Test. The data indicated the process as adequate, according to the hygienic conditions and that both the physicochemical and the microbiological analyses revealed all samples in accordance with Brazilian standards. The coconut water presented itself safe for consumption after bottled and stored at $10^{\circ} \mathrm{C}$ for 48 hours. A light change in the product color was observed after the storage, but the change had no influence on the product acceptability.
\end{abstract}




\section{REFERÊNCIAS BIBLIOGRÁFICAS}

1 ABIA. Compêndio da legislação de alimentos. Resolução n. 12 e 13 de 1978 da Comissão Nacional de Normas e Padrões para Alimentos. Fixa padrões de identidade e qualidade para alimentos (e bebidas). São Paulo, 1996. p. 7.2 (78)

2 ÁGUA de coco: o elixir da longa vida. Saúde, São Paulo, n. 12, p. 3437, 1984.

3 ANZALDÚA-MORALES, A. La evaluación sensorial de los alimentos en la teoría y la práctica. Chihuahua, México : Universidad Autónoma de Chihuahua/Facultad de Ciencias Químicas, 1990. p. 80-171.

4 APHA. Compendium of methods for microbiological examination of foods. Washington : Marvin L., 1976. 601 p.

5 SEBRAE/SUDENE/CEAG-SE. Diagnóstico das empresas de beneficiamento do coco no Estado de Sergipe. Sergipe, 1979. p. 35-93.

6 EMBRAPA. Centro Nacional de Pesquisas do Coco (CNPCo). Relatório técnico anual do Centro Nacional de Pesquisa do Coco (1990-92). Aracajú, 1993. p. 21-23.

7 CURSINO, M. M., SABAA-SRUR, A., LOURENÇO, N., PEREIRA, W. Contribuição à industrialização da água de coco (Cocus nucifera, L.) verde. Rio de Janeiro : Universidade Federal do Rio de Janeiro/Depto. de Tecnologia de Alimentos/IT, 1996.

8 INTERNATIONAL COMISSION OF MICROBIOLOGICAL SPECIFICATIONS FOR FOODS (ICMSF). Microbial ecology of foods, foods commodities. New York : Academic Press,1980. $997 \mathrm{p}$.

9 INSTITUTO ADOLFO LUTZ. Normas Analíticas do Instituto Adolfo Lutz. 2. ed. São Paulo : Guanabara Dois, 1981. 331 p.

10 MACIEL, M. I., OLIVEIRA, S. L., SILVA, I.P. Effect of different storage conditions on preservation of coconut (Cocus nucifera) water. Journal of Processing and Preservation, v. 16, p. 13-22, 1992.

11 MARQUES, A. L. V. Água de coco. Fortaleza : Sociedade Cearense de Ginecologia e Obstetrícia, 1982. (Informativo SOCEGO II, $\left.n^{\circ} 92\right)$. 
12 TEIXEIRA, E. A. M. Contribuição a industrialização do coco (Cocus nucifera), leite de coco e coco ralado. Fortaleza, 1986.

188 p. Tese (Mestrado), Tecnologia de Alimentos, Universidade Federal do Ceará. 